Article

\title{
The effect of niobium and titanium in base metal and filler metal on intergranular corrosion of stainless steels
}

\author{
Marcin Żuk ${ }^{1, *}$, Artur Czupryński' ${ }^{1}$ Dariusz Czarnecki ${ }^{1}$, Tomasz Poloczek ${ }^{1}$ \\ ${ }^{1}$ Silesian University of Technology, Poland \\ Artur Czupryński, Ph.D. Eng., artur.czuprynski@polsl.pl; \\ Dariusz Czarnecki, Eng., darekczarnecki95@gmail.com; \\ Tomasz Poloczek, M.Sc. Eng., tomasz.poloczek@polsl.pl; \\ * Correspondence: Marcin Żuk, M.Sc. Eng., marcin.zuk@polsl.pl \\ Received: 01.04.2019; Accepted: 15.06.2019
}

\begin{abstract}
The article describes the effect of alloyed additives in base material and filler metal on intergranular corrosion. Steel $1.2 \mathrm{~mm}$ thick, titanium-stabilized ferritic stainless steel and titanium and niobium-stabilized ferritic stainless steel have been surfacing method MAG (135). The specimens received was subjected to macro and microscopic tests, hardness tests and the intergranular corrosion resistance test. The study showed a higher corrosion resistance of niobium and titanium stabilized steel from titanium-stabilized steel. In addition, a ferritic fine-grain structure was found in the padding axis made with the use of filler metal with titanium and niobium microadditives.
\end{abstract}

Keywords: ferritic stainless steel; intergranular corrosion; surfacing

\section{Introduction}

Steel grades certified as high-alloy stainless are widely used in the industry, among others due to their properties, especially corrosion resistance. However, the advantages of corrosion resistance significantly affect the price of the basic material. The high price of stainless steels is dictated, among others using expensive alloy components such as chromium and nickel for their production. Stainless steel, in order to be resistant to corrosion, should contain more than $12.5 \%$ of chromium in its composition. Typical stainless steels are austenitic steels having additionally nickel (more than $8 \%$ ) and molybdenum. Austenitic steels have very good corrosion resistance (including $\mathrm{Cr}-\mathrm{Ni}-\mathrm{Mo}$, with a reduced carbon content, stabilized with micro additives), susceptibility to plastic machining and relatively good weldability. The desire to reduce the cost of production of elements has led to a wider use of stainless ferritic steels, however, in manufacturing processes requiring relatively high heating of this type of steel, it is very likely that their structure changes due to grain growth and the formation of chromium carbides at the grain boundaries, which in turn may lead to intergranular corrosion. Ferritic steels are widely used in the automotive industry, where such material allows the element to be made without additional corrosion protection processes, along with the predicted longer working time in the road environment. The low thickness of such materials allows welding without bevelling, using a minimum gap, resulting in full penetration in the joint, with minimal edge preparation cost. Lowering costs, which is the material configuration, the native material-binder, requires checking how specific materials behave during the corrosive environment after welding $[1 \div 14]$.

\section{Research}

The aim of the work was to investigate the effect of alloy additives contained in ferritic stainless steels and a binder dedicated to their surfacing, on the course of intergranular corrosion in the padding weld and in the Heat Affected Zone (HAZ). The materials used for the research were ferritic stainless steel grades X2CrTiNb18 (AISI 441) and X2CrTi12 (AISI 409) and additional materials in the form of solid wires stabilized: niobium (X3CrNb17; AISI 430Nb) and titanium and niobium (X2CrTiNb18; AISI 441). Figure 1 shows the microstructures of native materials, and their chemical composition in Table I (the test was performed with a spark spectrometer).

In the case of $\mathrm{X} 2 \mathrm{CrTiNb} 18$ steel, the structure of the native material is a fine-grained ferrite with visible grain boundaries, also yellow titanium carbonitride precipitates and very fine niobium carbide separation are found at the grain boundaries. X2CrTi12 steel is also characterized by a fine ferritic structure with no clear ferrite boundaries. Only the releases of titanium carbonitrides are noticeable. The releases of titanium and 
niobium in these steels are intended to prevent the formation of chromium carbides on the grain boundaries, which can lead to intergranular corrosion.

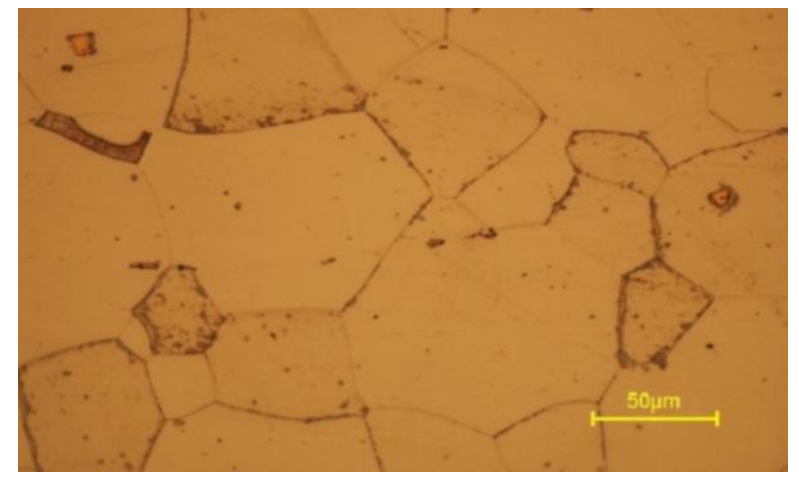

(a)

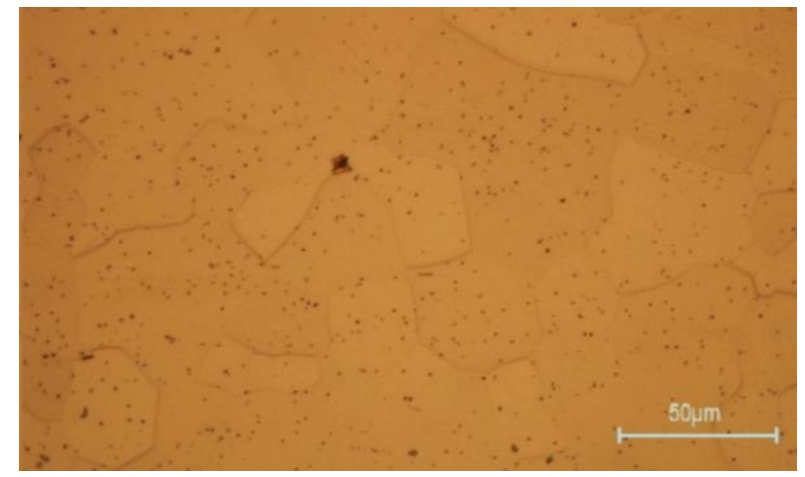

(b)

Fig. 1. Base material: a) $\mathrm{X} 2 \mathrm{CrTiNb} 18$, b) $\mathrm{X} 2 \mathrm{CrTi12}$. Etching in aqua regia

Table I. Chemical composition of base metal according to PN-EN 10088-1: 2014-12

\begin{tabular}{|c|c|c|c|c|c|c|c|c|c|}
\hline \multirow[b]{2}{*}{ Steel } & \multicolumn{9}{|c|}{ Content of elements, wt. [\%] } \\
\hline & C & $\mathrm{Cr}$ & $\mathrm{Ni}$ & $\mathrm{Ti}$ & $\mathrm{Nb}$ & Mn & Si & Mo & $\mathbf{P}_{\max }$ \\
\hline Norm & $<0.03$ & $17.5 \div 18.5$ & - & $0.1 \div 0.6$ & $<1$ & $<1$ & $<1$ & - & 0.04 \\
\hline X2CrTiNb18 & 0.025 & 18.09 & 0.303 & 0.174 & 0.343 & 0.357 & 0.594 & 0.064 & 0.02 \\
\hline Norm & $<0.03$ & $10.5 \div 12.5$ & - & $<0.65$ & - & $<1$ & $<1$ & - & 0.04 \\
\hline X2CrTi12 & 0.022 & 11.91 & 0.183 & 0.210 & $<0.005$ & 0.401 & 0.683 & 0.037 & 0.021 \\
\hline
\end{tabular}

\section{Surfacing}

The surfacing process was carried out using the MAG method (135). Due to the low thickness of the native material $(1.2 \mathrm{~mm})$, padding welds were obtained whose geometry can be compared with butt welds in butt joints with the preparation of material edges on I. The native material was cut to $200 \times 100 \mathrm{~mm}$ and surfaced along the long side. An active M22 gaseous shielding mixture $\left(96 \% \mathrm{Ar}+4 \% \mathrm{O}_{2}\right)$ according to EN ISO 14175 was used. The use of shielding gas with the addition of oxygen reduced the surface tension of the padding weld's metal, which may increase its spread on the surface. An additional material in the form of a solid wire with a diameter of $1.0 \mathrm{~mm}$ was used. The surfacing process was carried out manually at an average speed of approx. $10 \mathrm{~mm} / \mathrm{s}$. The remaining surfacing parameters are: 90 A current and $17 \mathrm{~V}$ arc voltage. The heat input of the deposition was approx. $0.122 \mathrm{~kJ} / \mathrm{mm}$.

The welding was carried out in four configurations, the native material - additional material, presented in the table II.

Table II. Material configuration used during the surfacing process

\begin{tabular}{ccc}
\hline $\begin{array}{c}\text { Sample } \\
\text { number }\end{array}$ & Native material & Additional material \\
\hline 1 & $\mathrm{X} 2 \mathrm{CrTiNb} 18$ & $\mathrm{X} 2 \mathrm{CrTiNb} 18$ \\
2 & & $\mathrm{X} 3 \mathrm{CrNb} 17$ \\
3 & $\mathrm{X} 2 \mathrm{CrTi12}$ & $\mathrm{X} 2 \mathrm{CrTiNb} 18$ \\
4 & & $\mathrm{X} 3 \mathrm{CrNb} 17$ \\
\hline
\end{tabular}

\section{Scope of research of the obtained padding welds}

After the surfacing process, a number of tests were carried out to assess the structure, hardness and resistance to intergranular corrosion of the steel under test in the HAZ and padding weld. Among others, macroscopic, microscopic, hardness measurements and intergranular corrosion resistance tests were performed.

For macro and microscopic examinations, samples cut across the padding weld were used. The crosssections obtained in this way were properly prepared and digested in the aqua regia solution $(30 \mathrm{ml}$ of hydrochloric acid $+10 \mathrm{ml}$ of nitric acid $(\mathrm{V})+40 \mathrm{ml}$ of demineralized water) during $30 \div 40 \mathrm{~s}$. 
The hardness measurement was carried out using the Vickers method according to PN-EN ISO 6507 and it was made in one measurement line according to the diagram shown in figure 2 . The indentation load was $0.2 \mathrm{~N}$.

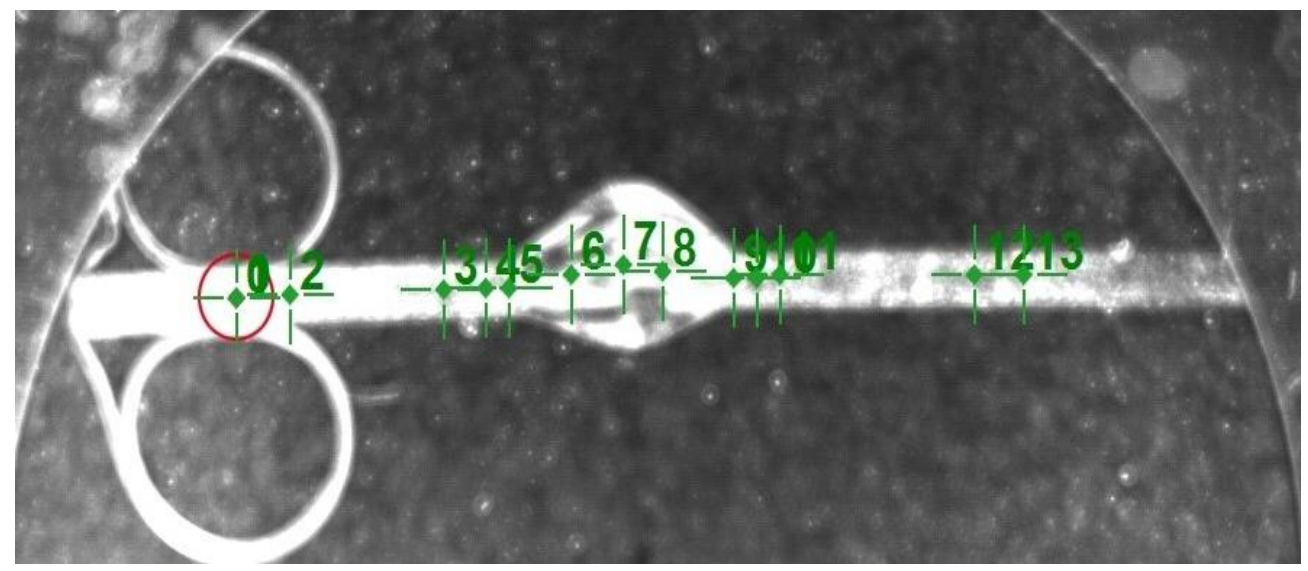

Fig. 2. Scheme of microhardness measurement

The test for resistance to intergranular corrosion was carried out on the basis of ASTM A 262, Procedure $\mathrm{E}$, which is recommended for stainless steels with the addition of elements stabilizing the structure. This study reveals that the effectiveness of steel stabilization with micro-additives, but also reveals changes in corrosion resistance after welding, giving information on the susceptibility to formation of chromium carbides at the grain boundaries. The test consists in placing material samples in a laboratory flask on copper filings with electrolytic purity (content of pure Cu copper element $99.99 \%$ ). The preparation was immersed in a corrosive solution. The solution was heated to the boiling point (about $102{ }^{\circ} \mathrm{C}$ - experimentally determined using a mercury-free thermometer) and maintained for $24 \mathrm{~h}$. The corrosion solution contained $100 \mathrm{~g}$ copper (VI) sulphate (II), $700 \mathrm{ml}$ of distilled water and $100 \mathrm{ml}$ of sulphuric acid (VI) and $1000 \mathrm{ml}$ of demineralized water. The samples after removal from the corrosion solution were examined for the presence of discontinuities in the structure, occurrence of cracks on the surface. As a standard, in addition, samples are bent on the mandrel by $180^{\circ}$ to break the continuity of the structure (bending test were not made due to the size of the surfaced samples) according to ASTM A 262-02a.

\section{Analysis of the results}

The macroscopic studies revealed significant differences in the structure of native material and in the padding weld in four different configurations - native material - additional material (Fig. 3). In the case of sample 1, (Table II, Fig. 3a), no clear grain growth in the HAZ was observed, and in the padding weld's axis a clear area of the fine-grained structure was observed. Also visible were oblong ferrite grains, whose spatial orientation is the result of the direction of heat dissipation during the welding. Compared with sample 1, in sample 2 (table II, fig. 3b), there was a slight increase in grain size in the heat affected zone, but more importantly, a coarse crystal structure was observed in the area of the padding weld's axis. This may be due to the lack of a stabilizing addition in the form of titanium in the composition of the additive material, which forms crystals in the liquid despite its heterogeneous nature. Sample 3 is a native material in the form of ferritic steel stabilized only with titanium (Table II), which as a result of surfacing contributed to the grain growth in the HAZ. The additional material in the form of a double stabilized electrode wire (X2CrTiNb18) resulted in a very similar structural system as in sample 1, i.e. fine grain in the padding weld's axis and elongated ferrite grains in the direction of heat dissipation (Fig. 3c). Sample 4 is a native material stabilized with titanium surfaced with a niobium-stabilized binder (Table II). This material configuration contributed to the grain growth in the heat affected zone and the largest grain size increase in the padding weld (Fig. 3d).

Analysis of the microstructure confirms the results of macrostructural investigations. The samples were characterized by a ferritic structure with varying degrees of grain growth and precipitations. In sample 1 after application, the HAZ microstructure was fine-grained with numerous titanium and niobium precipitates (Fig. 4a). The precipitation of titanium carbonitrides (Fig. 4b) and niobium carbides (Fig. 5) was also found in the padding weld. 


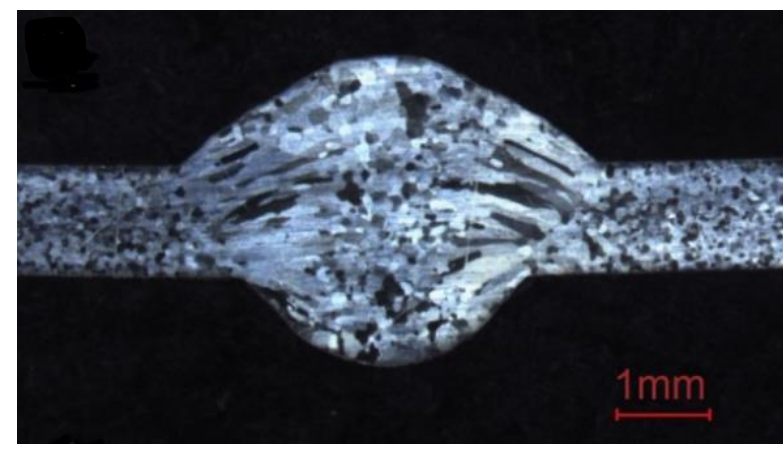

(a)

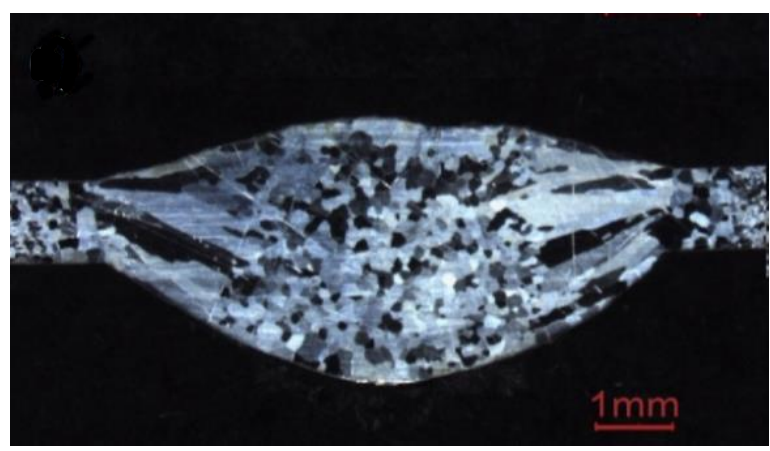

(c)

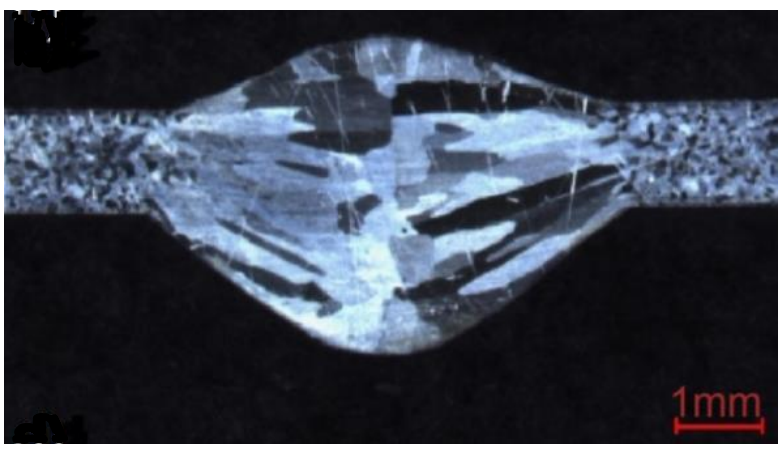

(b)

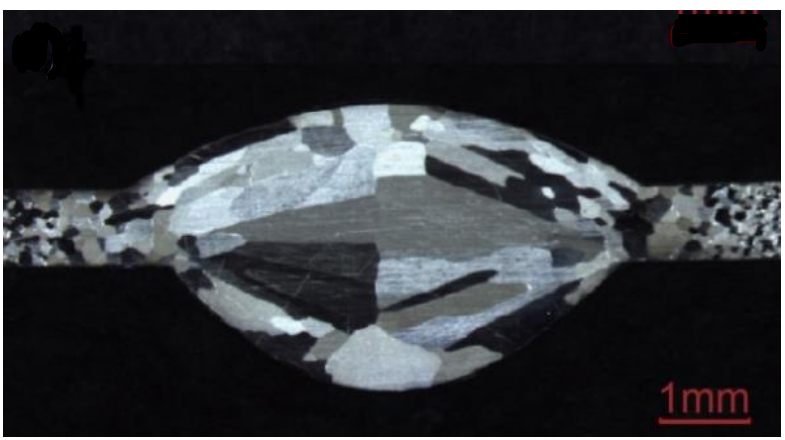

(d)

Fig. 3. View of macrostructure of specimens after surfacing by welding: a) specimen 1, b) specimen 2, c) specimen 3, d) specimen 4, (material configuration in table II). Etching in aqua regia

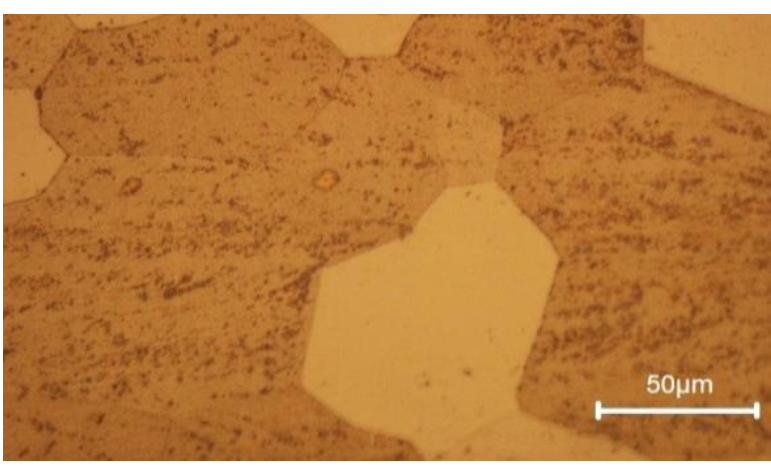

(a)

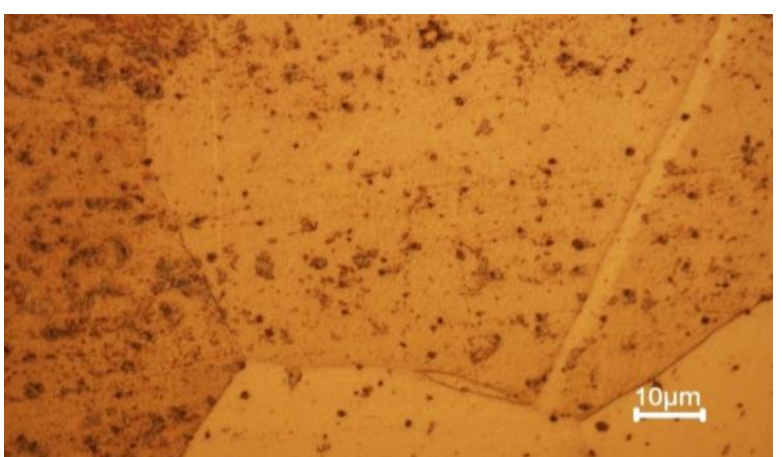

(b)

Fig. 4. View of microstructure specimen 1: a) HAZ, b) pad weld. Etching in aqua regia

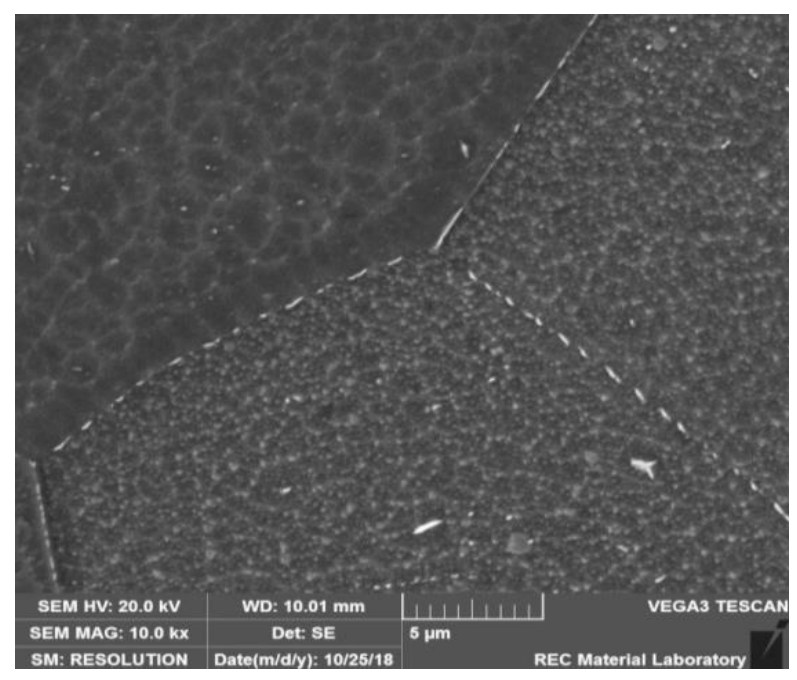

(a)

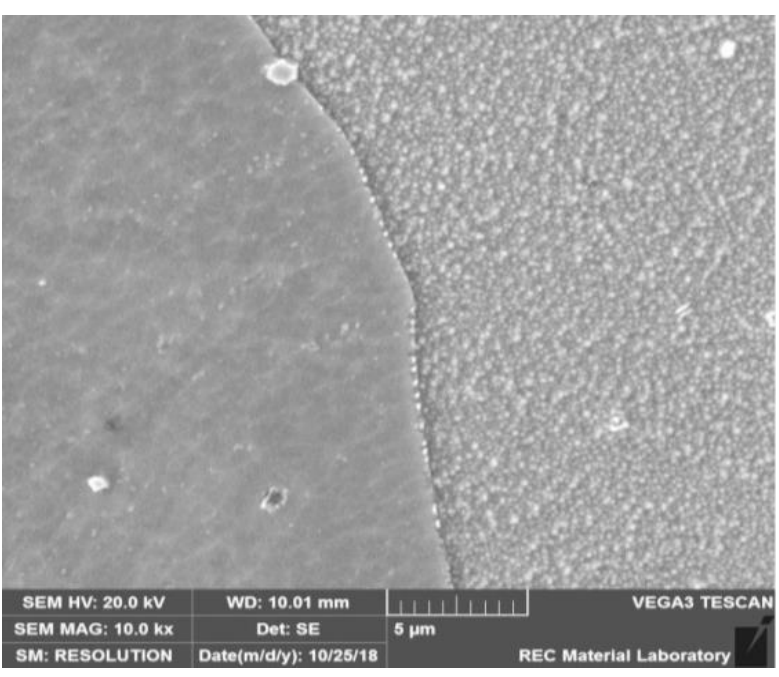

(b)

Fig. 5. Separation at grain boundaries in specimen 1: a) HAZ, b) pad weld. Etching in aqua regia 
In the case of sample 2 (Fig. 6a), a partial grain growth was noticeable in the heat affected zone, however, precipitations were visible as in the first case. The weld on sample 2 (Fig. 6b) had a coarse grain structure, this may be due to too little stabilizing elements. The structure in HAZ of sample 3 (Fig. 7a) was characterized by a large grain with titanium carbonitride precipitates. No addition of niobium led to significant grain growth. A fine-grained structure with titanic and niobium precipitates could be observed in the padding weld (Fig. 7b). Sample 4 was characterized by a large grain growth in the HAZ with numerous titanium precipitates, whereas in the padding weld a rapid grain growth occurred (Fig. 8a and 8b).

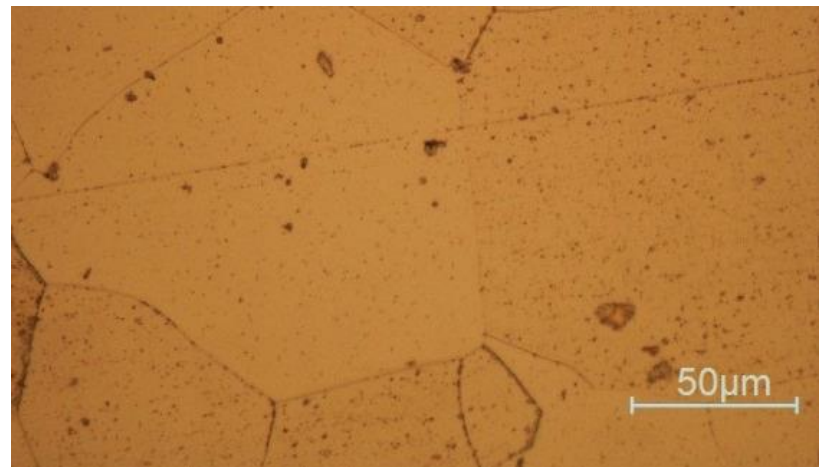

(a)

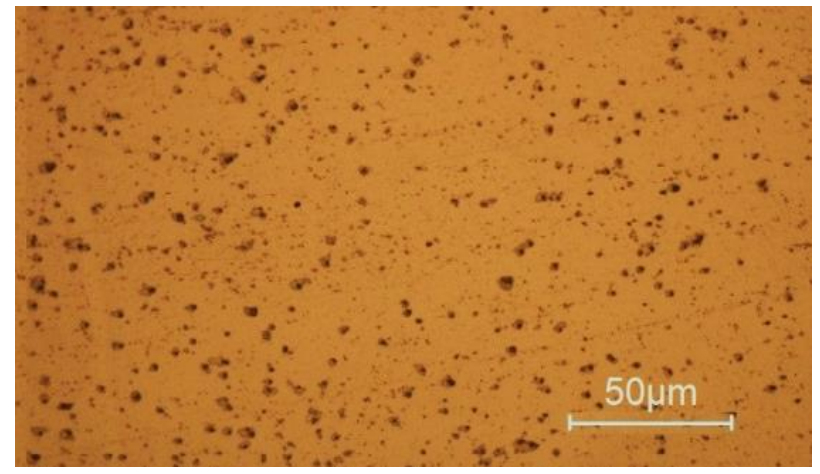

(b)

Fig. 6. View of microstructure specimen 2: a) HAZ, b) pad weld. Etching in aqua regia

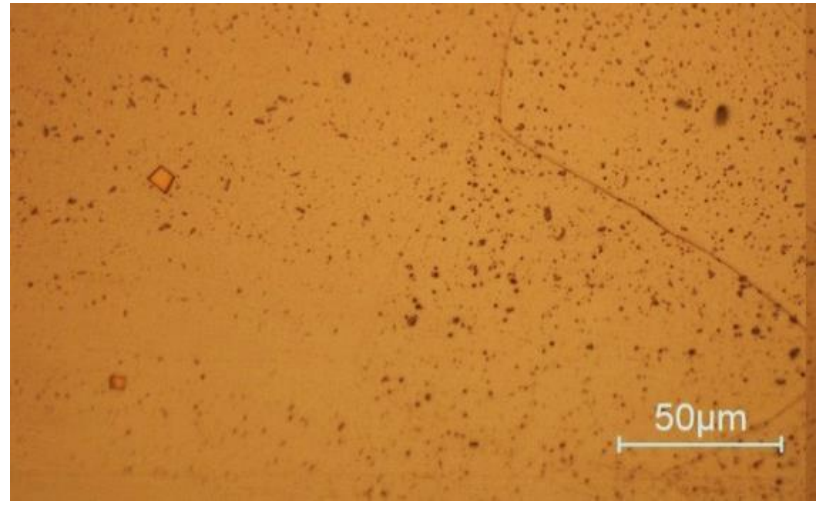

(a)

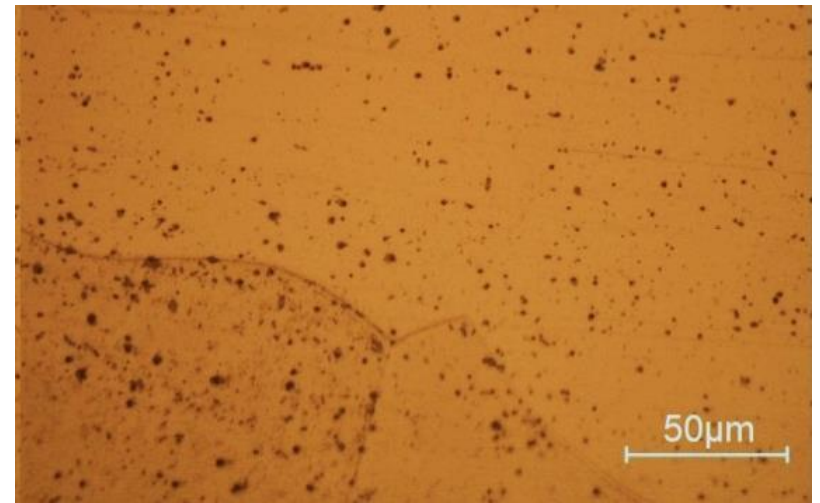

(b)

Fig. 7. View of microstructure specimen 3: a) HAZ, b) pad weld. Etching in aqua regia

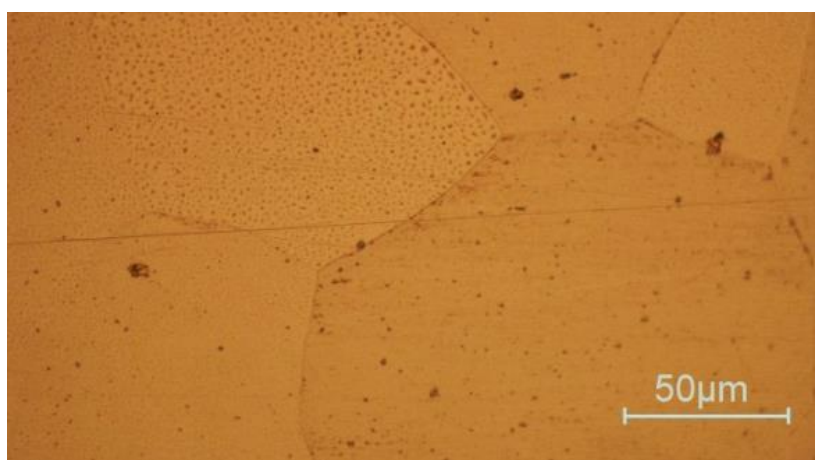

(a)

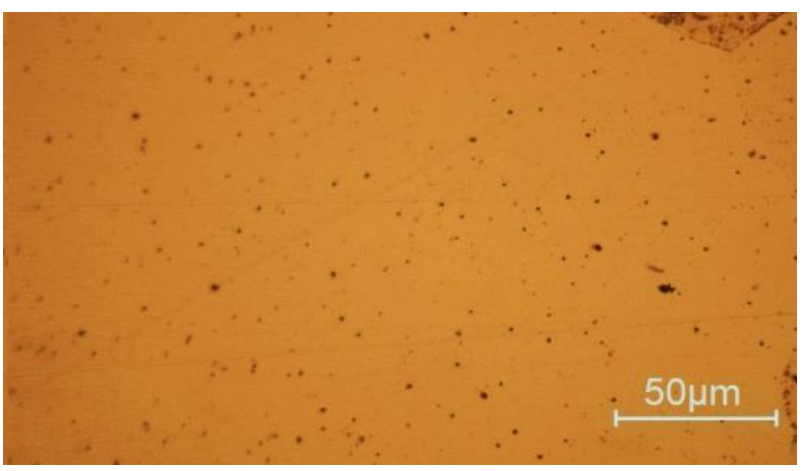

(b)

Fig. 8. View of microstructure specimen 4: a) HAZ, b) pad weld. Etching in aqua regia

Hardness measurements carried out in all samples showed that the native material in the form of steel stabilized with titanium and niobium (samples 1 and 2) is slightly harder than steel stabilized only with titanium (samples 3 and 4) and amounts to approximately 170 HV0.02 compared to approx. 140 HV0.02. The heat affected zone in all cases showed a higher hardness than the native material, while in all cases the highest hardness values were obtained in the padding welds (Fig. 9). The padding weld made with the use of additional material stabilized with titanium and niobium is characterized by a higher hardness than the layer surfaced with a binder stabilized only with niobium. 


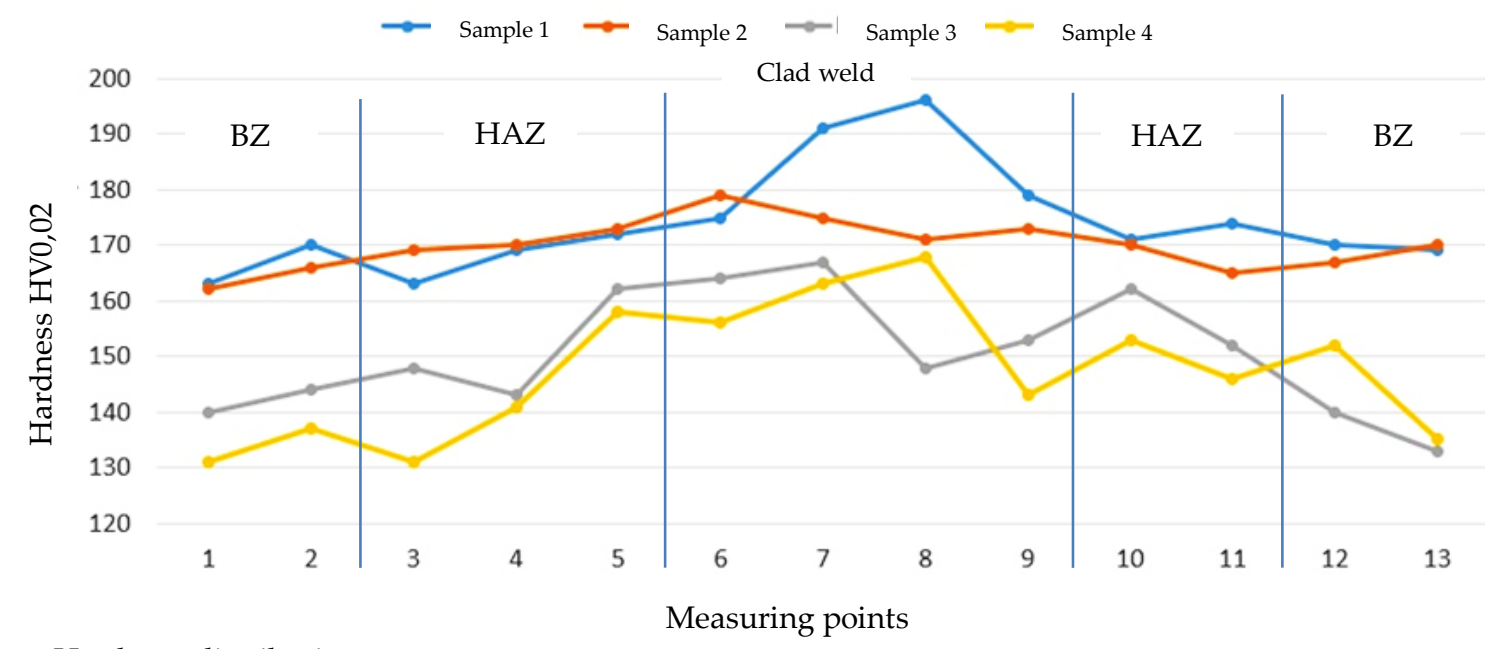

Fig. 9. Hardness distributions

Testing the resistance to intergranular corrosion of padding welds showed that samples 1 and 2 had a relatively high corrosion resistance. On the basis of visual inspections of padding welds (Fig. 10) and observations of macroscopic (Fig. 11) and microscopic (Fig. 12) specimens, there were no surface and structural incompatibilities characteristic of intergranular corrosion. In the heat affected zone, inclusions of titanium and niobium are visible. The padding weld's material was not affected by corrosion. The samples were consistent after the corrosion test. In the case of sample 3 there was a loss of material cohesion at the grain boundaries in the HAZ area (Fig. 13a), and microscopic images showed defects at the grain boundaries (Fig. 14a and Fig. 15). In the case of sample 4, the nature of changes in the material structure in the HAZ was similar to the changes in sample 3 but was characterized by lower intensity (Fig. 10d, Fig. 13b and Fig. 14 b). The padding weld's surface has not been breached. In spite of the clear intergranular corrosion, the sample 4 did not lose its cohesion in the heat affected zone but applying force in this place would cause the material to break.

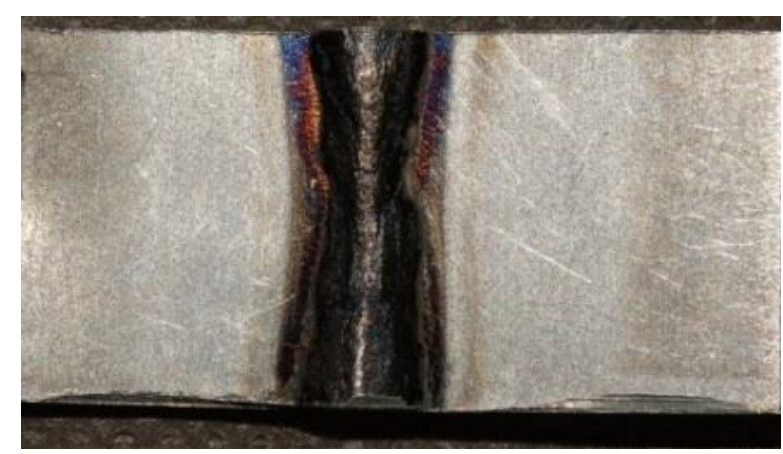

(a)

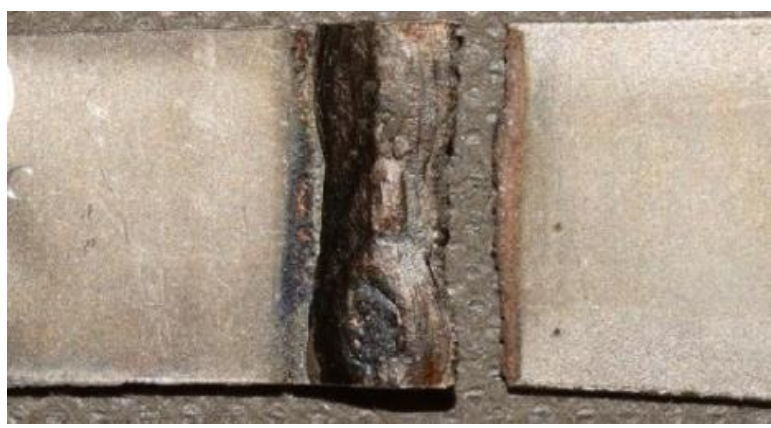

(c)

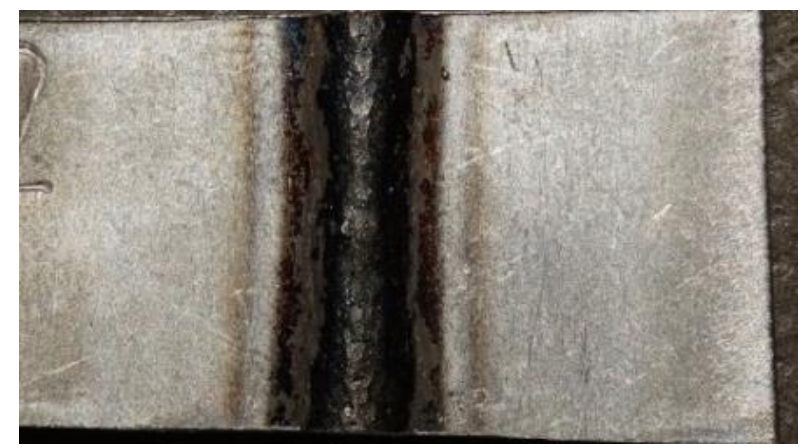

(b)

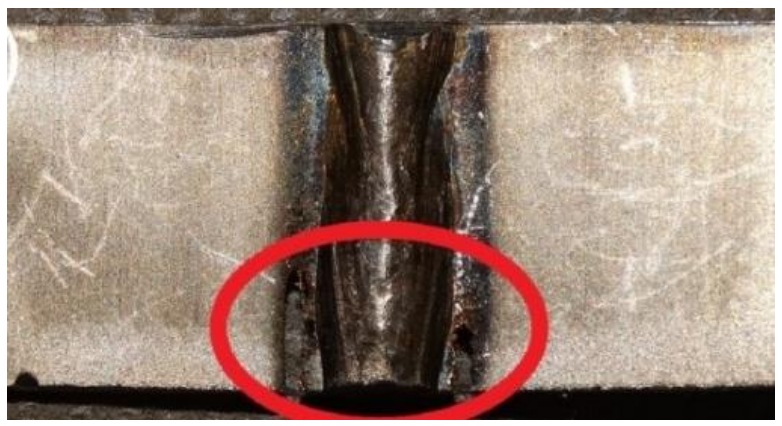

(d)

Fig. 10. View of specimens after bathing in a corrosive solution 


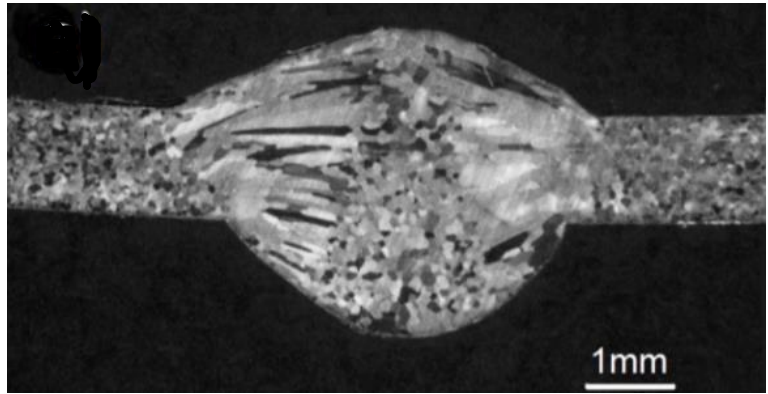

(a)

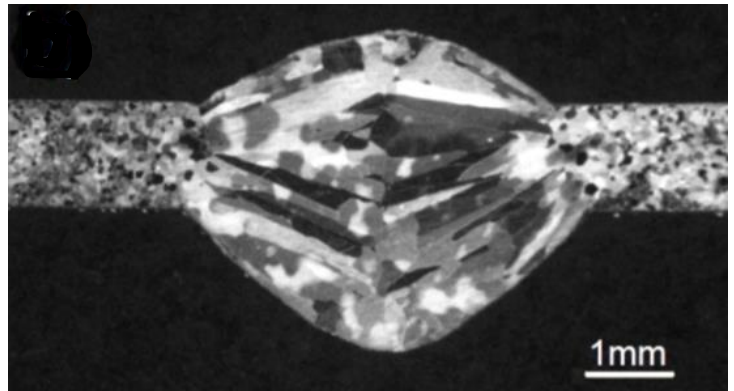

(b)

Fig. 11. Macrostructure of HAZ: a) specimen 1, b) specimen 2 after a corrosion test. Etching in aqua regia

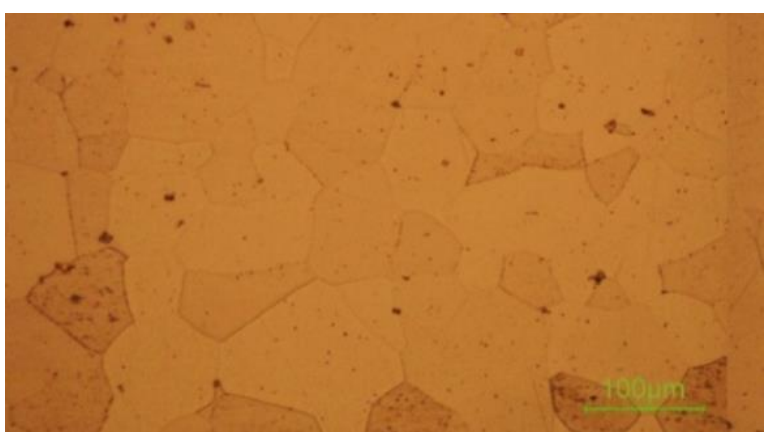

(a)

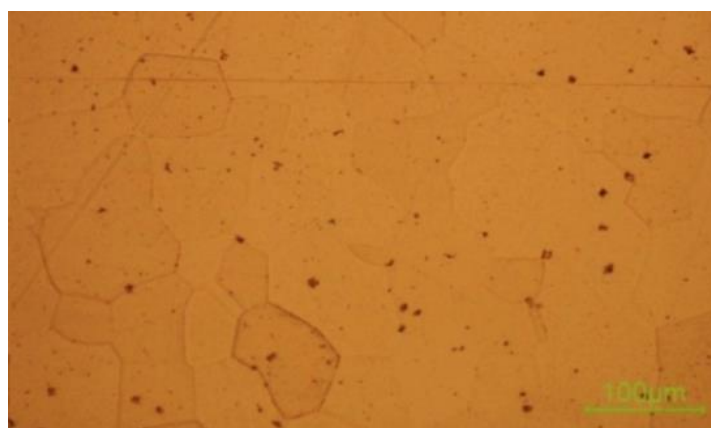

(b)

Fig. 12. Microstructure of HAZ: a) specimen 1, b) specimen 2 after a corrosion test. Etching in aqua regia

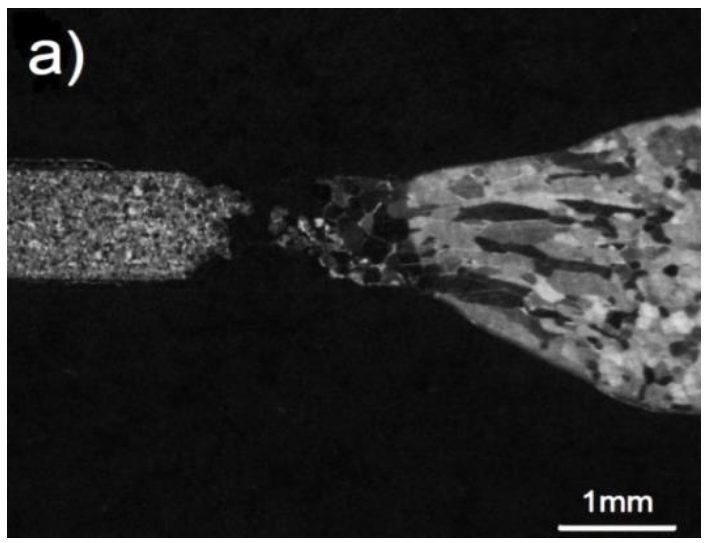

(a)

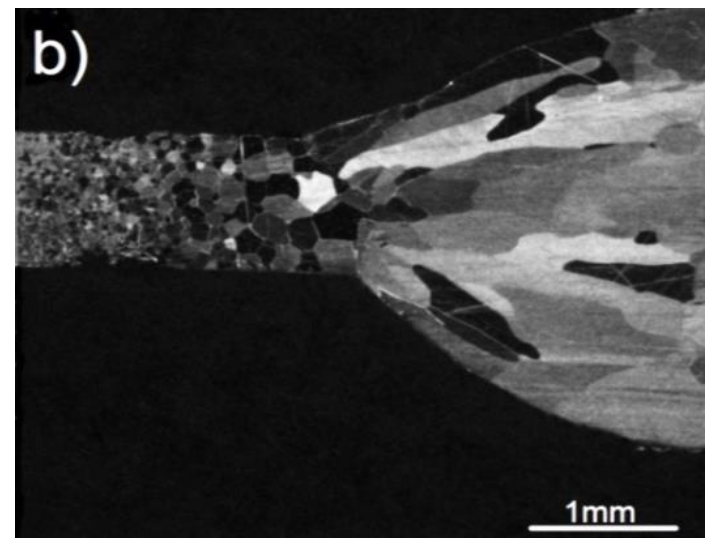

(b)

Fig. 13. Macrostructure of HAZ: a) specimen 3, b) specimen 4 after a corrosion test. Etching in aqua regia

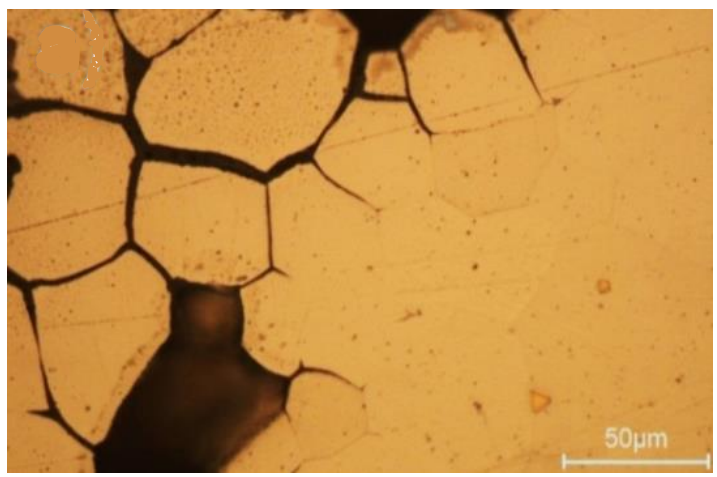

(a)

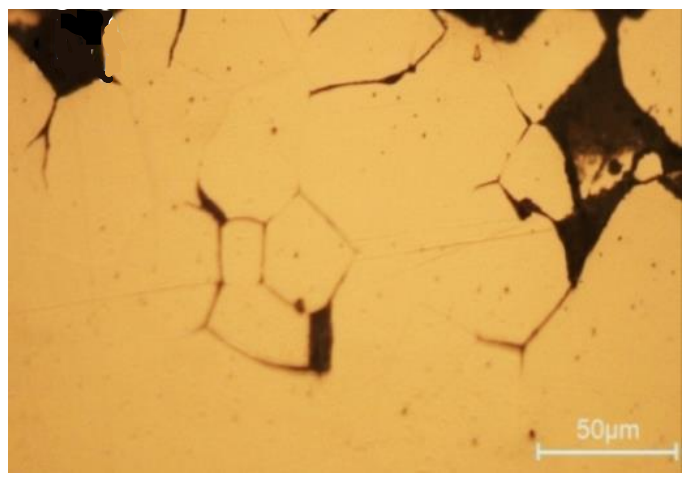

(b)

Fig. 14. Microstructure of HAZ: a) specimen 3, b) specimen 4 after a corrosion test. Etching in aqua regia 


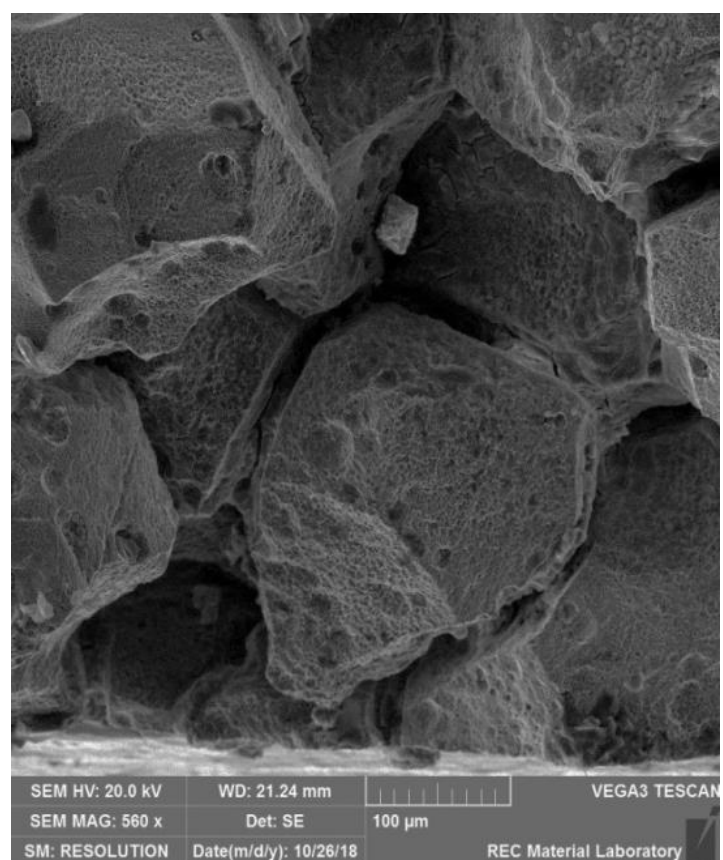

Fig. 15. Microstructure of HAZ specimen 3 after a corrosion test

\section{Summary}

The results of the conducted research indicate that the use of material stabilized at the same time with titanium and niobium limits the growth of grain in the heat affected zone and promotes fine-grained crystallization in the padding weld. Titanium and niobium during the surfacing show a strong chemical affinity for carbon, forming carbon compounds and limiting the binding of carbon to chromium, consequently limiting the depletion of crystals to chromium. As a result, in spite of the influence of the surfacing heat cycle, a sufficiently high resistance to intergranular corrosion of the material is maintained. This is particularly important in the case of welding processes introducing a large amount of heat to the material, which may promote the formation of chromium carbides at the grain boundaries. However, stabilization with niobium alone in the test conditions is not sufficient to inhibit the grain growth in the HAZ of the native material and to obtain a fine-grained structure without the precipitation of chromium carbides. This may be confirmed by the slight grain growth in the heat affected zone of the sample 2, after mixing of the base material and binder. In the case of titanium stabilized native material, there was a significant grain growth in the HAZ, which promoted the progress of intergranular corrosion, regardless of whether the additional material was stabilized with titanium and niobium, or niobium itself. The padding welds in both cases had good and comparable resistance to intergranular corrosion. The double stabilized material exhibited a higher hardness than the material stabilized with only one of these elements.

Conflicts of Interest: The authors declare no conflict of interest.

\section{References}

[1] Woszek M., Słania J., Golański G., Influence of welding process on microstructure of ferritic stainless steels. Welding Technology Review, 2017, Vol. 87(4), 15-18. [CrossRef]

[2] Łabanowski J., Głowacka M., Discoloration of the surface of welded joints of corrosion-resistant steel. Welding Technology Review, 2008, Vol. 80(6), 3-6.

[3] Banaś J., Głownia J., Stypuła B., Kalandyk B., Intergranular pitting and abrasive corrosion of duplex 25Cr-5Ni-6Mo stainless cast steels with nitrogen. Inżynieria materiałowa, 1998, Vol. 19(3), 351-355.

[4] Meran C., Bilgin M.B., Fusion and friction stir welding of X6Cr17 stainless steel. Journal of Achievements in Materials and Manufacturing Engineering, 2016, Vol. 61(2), 403-409. [Hyperlink]

[5] Lippold J.C., Kotecki D.J., Welding Metallurgy and Weldability of Stainless Steels. Wiley, 2005.

[6] Raabe D., Lüucke K., Textures of ferritic stainless steels. Materials Science and Technology, 1993, Vol. 9(4), $302-312$. [CrossRef]

[7] Fujita N., Kikuchi M., Ohmura K., Suzuki T., Funaki S., Hiroshige I., Effect of Nb on high-temperature properties for ferritic stainless steel. Scripta Materialia, 1996, Vol. 35(6), 705-710. [Crossref] 
[8] Jeong K.K., Yeong H.K., Jong S.L., Kyoo Y.K., Effect of chromium content on intergranular corrosion and precipitation of Ti-stabilized ferritic stainless steels. Corrosion Science, 2010, Vol. 52(5), 1847-1852. [CrossRef]

[9] Rogalski G., Jurkowski M., Łabanowski J., Fydrych D., Influence of surface condition after welding on corrosion resistance of Austenitic stainless steel AISI 304, Biuletyn Instytutu Spawalnictwa, 2018, Vol. 62(1), 24-29.

[10] Kułakowski M., Rokosz K., Alloyed austenitic, ferritic and duplex steels used in transport. Autobusy: technika, eksploatacja, systemy transportowe, 2017, Vol. 18(7-8), 357-362.

[11] Wciślik W., Kossakowski P., Sokołowski P., Stainless steel in building structures - advantages and examples of application. Structure and Environment, 2017, Vol. 9(3), 191-198.

[12] Brytan Z., How to heat treat properly stainless steels? Stal. Metale \& Nowe Technologie, 2016, Vol. 1-2, 62-64.

[13] Ryś J., Witkowska M., Ratuszek W., Zielińska-Lipiec A., Effect of annealing temperature on texture and structure of duplex stainless steels. Inżynieria Materiatowa 2004, Vol. 3, 186-189.

[14] Properties of corrosion-resistant steels, Euro Inox, Luksemburg, 2002, 1-24.

(C) 2019 by the authors. Submitted for possible open access publication under the terms and conditions of the Creative Commons Attribution (CC BY) license (http://creativecommons.org/licenses/by/4.0/). 